\title{
Equipe de enfermagem no cuidado à criança com doença de Pompe em terapia intensiva
}

\author{
Nursing team in care for children with Pompe disease in intensive care \\ Equipo de enfermería en la atención de niños con enfermedad de Pompe en cuidados intensivos
}

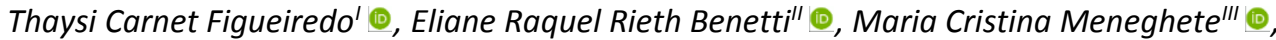 \\ Rosane Teresinha Fontana ${ }^{\prime \prime \prime} \odot$, Maria Simone Vione Schwengber ${ }^{\prime V} \odot$, Vivian Lemes Lobo Bittencourt ${ }^{\prime \prime \prime} \odot$ \\ 'Universidade Federal do Pampa, Uruguaiana, RS, Brasil; "Universidade Federal de Santa Maria, Santa Maria, RS, Brasil; \\ "'Universidade Regional Integrada do Alto Uruguai e das Missões, Santo Ângelo, RS, Brasil, \\ IV Universidade Regional do Noroeste do Estado do Rio Grande do Sul, Ijuí, RS, Brasil
}

\begin{abstract}
RESUMO
Objetivo: investigar o conhecimento e práticas da equipe de enfermagem em relação ao cuidado à criança com Doença de Pompe em terapia intensiva. Método: trata-se de um estudo descritivo com abordagem qualitativa. A coleta de dados foi realizada com entrevista semiestruturada com enfermeiras e técnicas em enfermagem que atuavam na Unidade de Terapia Intensiva Neonatal de um hospital do Rio Grande do Sul, após aprovação pelo Comitê de Ética em Pesquisa. Os dados foram analisados pela análise de conteúdo. Resultados: as profissionais enfatizaram experiências que superam procedimentos técnicos, na busca de fornecer um cuidado integral qualificado e seguro, para proporcionar vivências mais próximas de um lar para a criança e familiares. Conclusão: a equipe de enfermagem possui conhecimentos para o cuidado e atua de forma multiprofissional. Conclui-se que estudos relacionados às doenças raras oferecem subsídios para qualificar o cuidado de enfermagem.

Descritores: Doença de Depósito de Glicogênio Tipo II; Erros Inatos do Metabolismo; Unidades de terapia intensiva neonatal; Cuidados de enfermagem.
\end{abstract}

\begin{abstract}
Objective: to investigate nursing team knowledge and practices regarding care for children with Pompe disease in intensive care. Method: in this qualitative, descriptive study, data were collected by semi-structured interviews of nurses and nursing technicians working in the neonatal intensive care unit of a hospital in Rio Grande do Sul, after ethics committee approval. Data were subjected to content analysis. Result: the nurses emphasized experiences that go beyond technical procedures, in the endeavor to provide safe and qualified comprehensive care in order to provide experiences closer to a home for the children and their families. Conclusion: the nursing team was knowledgeable about care and worked in multidisciplinary manner. It was concluded that studies relating to rare disease offer input to inform nursing care.
\end{abstract}

Descriptors: Glycogen Storage Disease Type II; Metabolism, Inborn Errors; Intensive Care Units, Neonatal; Nursing Care.

\section{RESUMEN}

Objetivo: investigar el conocimiento y las prácticas del equipo de enfermería sobre el cuidado de niños con enfermedad de Pompe en cuidados intensivos. Método: en este estudio cualitativo descriptivo, los datos fueron recolectados mediante entrevistas semiestructuradas a enfermeras y técnicos de enfermería que laboran en la unidad de cuidados intensivos neonatales de un hospital de Rio Grande do Sul, previa aprobación del comité de ética. Los datos se sometieron a análisis de contenido. Resultado: las enfermeras destacaron experiencias que van más allá de los procedimientos técnicos, en el afán de brindar una atención integral segura y calificada con el fin de brindar experiencias más cercanas a un hogar para los niños y sus familias. Conclusión: el equipo de enfermería tenía conocimiento del cuidado y trabajaba de manera multidisciplinar. Se concluyó que los estudios relacionados con las enfermedades raras ofrecen información para informar la atención de enfermería.

Descriptores: Enfermedad del Almacenamiento de Glucógeno Tipo II; Errores Innatos del Metabolismo; Unidades de Cuidado Intensivo Neonatal; Atención de Enfermeira.

\section{INTRODUÇÃO}

A Doença de Pompe (DP) foi descoberta em 1932, pelo patologista Joannes Cassianus Pompe, durante a autópsia de uma criança de sete meses que teve a morte causada por hipertrofia miocárdica idiopática. Na oportunidade, o patologista visualizou acúmulo de glicogênio em vesículas no interior das fibras cardíacas ${ }^{1}$. A patologia, também conhecida como doença de armazenamento de glicogênio tipo Il ou deficiência de maltase ácida, caracteriza-se por ser uma doença neuromuscular autossômica recessiva, progressiva e multissistêmica, causada pelo acúmulo de glicogênio intralisossomal, pela atividade ineficaz da enzima Alfa-Glicosidase Ácida (GAA)². 
São reconhecidas na literatura três tipos da DP, que se diferenciam pela gravidade e faixa etária de manifestação, com início infantil clássico, início não clássico e início tardio. No início infantil clássico, os sinais e sintomas surgem nos primeiros meses de vida, evidenciados por miopatia, hipotonia, crescimento inapropriado, disfagia, dispneia e alterações auditivas $^{3}$. Na Europa, a prevalência da doença é de aproximadamente um caso por 283.000 habitantes e sabe-se também que, quando manifestada na forma infantil, apenas $25 \%$ permanecem vivas até um ano de idade ${ }^{4}$. No Brasil o primeiro caso de forma infantil da DP foi tratado e publicado em $2008^{5}$.

Avanços em relação ao diagnóstico precoce são recentes, como a possibilidade de identificação pelo teste do pezinho, com investigação bioquímica de doenças genéticas autossômicas, como DP, Doença de Gaucher e Doença de Fabry. Assim que o diagnóstico é definido, é fundamental o início de um tratamento com uma equipe de profissionais experientes na atenção à DP. Um aspecto essencial é o aconselhamento genético como um componente do cuidado e uma fonte de subsídios acerca da doença para pacientes e familiares, que ajudarão nas decisões atuais e futuras ${ }^{6}$.

Atualmente, o tratamento da doença é realizado com a implementação da terapia de reposição enzimática contínua, aliada com o suporte paliativo, inclusão de atividades físicas, fisioterapia, cuidados com dieta, farmacoterapia adequada e com suporte ventilatório em casos de maior comprometimento cardíaco ou pulmonar. Dessa forma, é possível proporcionar maior qualidade de vida e funcionalidade para os acometidos pela patologia. A progressão da doença se desenvolve inevitavelmente com o passar dos anos ${ }^{7}$. Com a terapia de reposição enzimática, a média de sobrevida estimada é de $54 \%$ a $72 \%{ }^{8,9}$. A alfa-glicosidase prolonga a sobrevivência e a qualidade de vida, em pacientes que necessitam ou não de ventilação mecânica ${ }^{10}$. Por mais que a medicação aja no prolongamento da estimativa de vida e regressão do agravo clínico da doença, essa progride para o declínio da capacidade da realização de atividades diárias e para uma menor qualidade de vida².

Na prática da enfermagem é fundamental que o cuidado à criança compreenda a atenção e a humanização aos pacientes e seus familiares durante a hospitalização, com a operacionalização de uma assistência acolhedora e dialógica ${ }^{11,12}$. Nesta perspectiva, a atuação da equipe de enfermagem é apontada como uma possibilidade de promoção de melhoria da capacidade de atender as necessidades e o cuidado à criança com DP e sua família ${ }^{13}$. Nessa conjuntura, o papel da enfermeira é fundamental pela sua atuação à frente do cuidado e com uma formação baseada na atuação holística, para propiciar o planejamento do cuidado efetivo, seguro, ético e dinâmico ${ }^{11}$.

Diante do exposto, questiona-se: quais os conhecimentos da equipe de enfermagem sobre a DP? Qual a atuação da equipe de enfermagem em relação à criança com DP em terapia intensiva? Assim, objetivou-se investigar o conhecimento e práticas da equipe de enfermagem em relação ao cuidado à criança com Doença de Pompe em terapia intensiva.

\section{MÉTODO}

Trata-se de uma pesquisa descritiva de abordagem qualitativa, desenvolvida em uma Unidade de Terapia Intensiva (UTI) neonatal, de um hospital de médio porte, localizado no noroeste do estado do Rio Grande do Sul ${ }^{14}$. Desde 2011 , a instituição presta atendimento a uma criança com DP, a qual é residente na instituição até os dias atuais, o que justifica a escolha intencional do local para pesquisa.

O primeiro contato com a instituição ocorreu com a Enfermeira Responsável Técnica, para apresentar o projeto de pesquisa e solicitar autorização para realizá-lo. Mediante aprovação para desenvolver a pesquisa, essa foi apresentada em uma reunião setorial para a equipe de enfermagem da UTI neonatal, composta por 19 técnicos em enfermagem e cinco enfermeiras. Ao término da explanação, foi disposta uma lista para preenchimento dos dados dos integrantes da equipe com interesse em participar. Foram agendadas entrevistas com os integrantes da equipe conforme a disponibilidade de cada um.

As participantes do estudo foram enfermeiras e técnicas em enfermagem que atuam no referido setor. Foram utilizados como critérios de inclusão: ser integrante da equipe de enfermagem atuante na UTI neonatal, em qualquer turno, e ter prestado assistência a paciente com a DP. Como critérios de exclusão: ser enfermeiro ou técnico em enfermagem em licença de qualquer natureza ou gozo de férias no período da coleta de dados.

Após a assinatura do Termo de Consentimento Livre e Esclarecido, em duas vias, as entrevistas semiestruturadas ocorreram em três dias do mês de outubro de 2019, nos turnos da manhã, tarde e noite, de forma única e individual, no local de trabalho, respeitando a disponibilidade das participantes. Seguiu-se um roteiro para coleta de dados sociodemográficos e laborais com informações sobre sexo, idade, turno de trabalho, tempo de exercício profissional e tempo de atuação na função na instituição. As perguntas específicas sobre DP e cuidados foram alicerçadas no Genetics Home Reference, Your Guide to Understanding Genetic Condition ${ }^{3}$.

As entrevistas foram gravadas utilizando-se um gravador digital com autorização das participantes e transcritas na íntegra para análise, segundo o método de análise de conteúdo temático nas etapas de pré-análise, exploração do material e tratamento dos resultados ${ }^{15}$. Após leitura exaustiva, procedeu-se a organização dos dados com codificação 
dos resultados, a inferência, extraindo-se categorias para, num terceiro momento, realizar a interpretação e a discussão dos dados com a literatura especializada no assunto. Após a realização da leitura flutuante, os dados foram codificados em unidades de registro, que sistematicamente foram agregados em duas categorias temáticas: conhecimento da equipe de enfermagem sobre a Doença de Pompe e tratamento; e práticas da equipe de enfermagem no cuidado à criança com doença de Pompe. Na fase de interpretação dos dados, foi retomado o referencial teórico, a fim de embasar as análises dando sentido à interpretação.

Asseguraram-se as exigências éticas e científicas preconizadas para pesquisas envolvendo seres humanos, mediante a Resolução 466/2012, do Conselho Nacional de Saúde, que dispõe sobre as diretrizes e normas regulamentadoras de pesquisas que envolvem seres humanos. O projeto foi aprovado pelo Comitê de Ética em Pesquisa, sob o CAAE n 15690619.4 .0000 .5354 e parecer $n=3.428 .965$, e todas as participantes foram esclarecidas sobre o projeto e assinaram o Termo de Consentimento Livre e Esclarecido. Para a apresentação dos resultados, as participantes foram codificadas como Participante 1 (P1), Participante 2 (P2), e assim sucessivamente.

\section{RESULTADOS E DISCUSSÃO}

Fizeram parte do estudo 11 profissionais da equipe de enfermagem, sendo destas nove técnicas em enfermagem e duas enfermeiras. As participantes, em sua maioria, referiram idade entre 26 e 35 anos (63,63\%), todas do sexo feminino, raça branca (100\%) e a maioria com atuação há, pelo menos, oito anos na área da enfermagem (72,72\%). A partir da análise das falas emergiram duas categorias: Conhecimento da equipe de enfermagem sobre a Doença de Pompe e tratamento; e práticas da equipe de enfermagem no cuidado à criança com Doença de Pompe.

\section{Conhecimento da equipe de enfermagem sobre a Doença de Pompe e tratamento}

Sabe-se que a DP é uma patologia rara, o que dificulta o acesso e propagação dos conhecimentos sobre o tema. Entretanto, a equipe demonstrou estar ciente da importância do entendimento sobre a patologia. Entre os conhecimentos abordados pela equipe de enfermagem sobre DP foi verificado o conhecimento sobre a raridade de sua ocorrência, gravidade, cronicidade, alta letalidade e progressão sistêmica da patologia.

[...] É doença degenerativa, nos músculos [...] foi deixando flácido, flácido, tanto é que quando ela veio conosco, tinha cinco meses (paciente), ela foi crescendo, ainda conseguia dar tchauzinho com a mão. Agora ela não faz mais nada disso, só consegue mexer a língua e os olhos, o resto foi. (P1)

[...] tem uma deficiência de enzima [...] faz com perda toda a força dos músculos, com progressão. (P6)

[...] quando era bebê com o passar dos dias ela não conseguia evacuar e mamar e foram investigar, daí que descobriram que era essa doença. (P3)

A DP é uma doença incomum, gradativa com elevada letalidade. Com a ocorrência da doença emerge a deficiência de GAA e a necessidade de reposição dessa enzima de forma sintética, na tentativa de amenizar os efeitos de progressão da patologia e proporcionar qualidade de vida ${ }^{16}$. Esse tratamento é contínuo e chamado de Terapia de Reposição Enzimática (TRE).

[...] ela (criança) tem falta de uma enzima, então ela repõe a cada 15 dias. Por causa dessa enzima que ela tá viva. (P5)

[...] fazendo as enzimas ela fica mais disposta, fica mais feliz. Quando está chegando perto de fazer as enzimas ela já começa a ficar mais cansada. (P3)

A terapia de reposição enzimática repõe a enzima, pois a Pompe ocorre pela deficiência das enzimas. Com a terapia a gente repõe as enzimas e faz com que o organismo consiga degradar o glicosídeo que fica depositado no organismo. É com Myozyme ${ }^{\circledR}$ o tratamento. (P9)

[...] conforme vai ganhando peso vai aumentando o número de frascos. (P11)

Doenças como essa, sem possibilidades de cura, são elegíveis para a modalidade de tratamento com cuidados paliativos ${ }^{17}$. Os cuidados paliativos têm como objetivo melhorar a qualidade de vida de pacientes e familiares por meio de assistência biopsicossocial, e como em qualquer outro tratamento, é necessário organização, planejamento e treinamento. Para o tratamento da DP, a TRE é realizada com administração de Maltase Ácida Recombinante Humana (alfa-glicosidase), com nome comercial de $M y o z y m e^{\circledR 18}$. A alfa-glicosidase é um tratamento efetivo para grande maioria dos pacientes com DP, todavia, esse tratamento não tem possibilidade curativa, o que torna necessária investigação aprofundada sobre a resposta individual à terapia ${ }^{19}$. A TRE é uma terapia que envolve boa parte da equipe multiprofissional, como médico, farmacêutico, enfermeira e técnico em enfermagem. No entanto, sua preparação é realizada pelas enfermeiras, com protocolo institucional, que norteia a preparação.

[...] a enfermeira fica monitorando. É feita endovenosa, então tem um preparo específico. (P2)

[...] é feita com bomba de infusão, inicia com volume bem baixinho e aumenta gradativamente conforme $o$ tempo, daí mede a temperatura, aumenta o volume se está tudo certo. O monitoramento é pela verificação 
dos sinais vitais. O médico dela que prescreve, e fica acompanhando, a farmácia separa no dia anterior e deixa para as enfermeiras diluírem. (P6)

Um estudo de caso, realizado em 2016, referiu que o meio científico mantém consenso sobre a eficácia da TRE, além de trazer evidências de seus benefícios para a clínica do paciente, contribuindo positivamente para a estabilização e desenvolvimento motor do paciente quando DP infanti ${ }^{20}$. De tal forma garante qualidade de vida aos pacientes, enquanto novos estudos não são desenvolvidos na busca de melhores tratamentos. Assim, envolve complexas situações, sendo fundamental a atuação de equipe multiprofissional. A preparação da TRE é aspecto primordial, e para garantir o processamento adequado da medicação é necessário seguir uma série de cuidados durante a diluição da enzima, para não comprometer sua estabilidade e eficácia, conforme referido nas falas a seguir.

[...] para diluir se deixa na temperatura ambiente, aí para a diluição ela tem que ser toda cuidadosa. Se faz lentamente com uma agulha $25 \times 7$, água destilada, colocando na parede do frasco, então, vai diluindo com movimentos circulares, pra não fazer bolhas, aspirar de dentro do frasco bem lentinha, para que ela não quebre as moléculas da enzima, e depois coloca no frasco de soro fisiológico, para fazer a infusão. É bem demorado, bem criterioso para poder fazer a diluição e administração. O equipo tem que ser isento de PVC $e$ tem que ter filtro. (P9)

[...] a gente lava (o acesso venoso central portocath) com $20 \mathrm{ml}$, faz um flushing e deixa salinizado por 24 horas. (P7)

O Ministério da Saúde brasileiro divulgou um relatório de recomendações para administração da TRE em DP. Entre suas orientações, a posologia indicada de alfa-glicosidase é de $20 \mathrm{mg} / \mathrm{kg}$, que deve ser infundido a cada 14 dias, por meio de via endovenosa. A determinação do volume total varia de acordo com o peso corporal, com tempo médio de infusão de quatro horas em bomba de infusão. Ainda, deve-se utilizar um pré-filtro $(0,2 \mu)$, além de infundir em etapas com volume e vazão graduais, respeitando o limite das taxas de infusões. 0 máximo da taxa de infusão inicial é 1 $\mathrm{mg} / \mathrm{kg} / \mathrm{h}$, podendo chegar a $2 \mathrm{mg} / \mathrm{kg} / \mathrm{h}$ a cada 30 minutos, após assegurar que o paciente está estável, tolerando a medicação, para então ir aumentando a vazão até chegar à taxa máxima de $7 \mathrm{mg} / \mathrm{kg} / \mathrm{h}$. A equipe de enfermagem verifica os sinais vitais ao finalizar cada etapa, sempre antes de seguir para próxima taxa de infusão ${ }^{18}$.

Os efeitos adversos referidos pela equipe não são específicos apenas desta TRE, mas são reações alérgicas gerais. A equipe de enfermagem demonstra conhecimentos necessários para atuar em situações de efeito adverso da medicação, além de manter monitoramento e avaliação constante do paciente, com estratégias definidas previamente.

[...] a gente fica monitorando para ver se não vai dar febre, monitorando ela. (P2)

[...] pode fazer uma reação alérgica, choque anafilático. (P11)

[...] alguma vermelhidãozinha, bolhas na pele, reação na pele. (P3)

[...] em caso de reação a gente comunica a enfermeira e ela comunica o médico do plantão. Sempre tem epinefrina já com dose prescrita. (P6)

Entre as reações adversas que podem ocorrer destacam-se as reações anafiláticas durante a infusão. No entanto, as reações que mais ocorrem e que necessitam de intervenções são bradpneia, taquicardia, taquipneia, tosse, vômito, prurido, erupções cutâneas e febre ${ }^{18}$. A equipe de enfermagem referiu a raridade, cronicidade, gravidade e progressão da patologia, além de identificar os sinais e sintomas característicos de DP, como hipotonia e comprometimento motor. Também demostraram conhecimentos necessários sobre a TRE, seus benefícios, possíveis efeitos adversos e intervenções necessárias nestes casos. Isso indica o envolvimento da equipe de enfermagem em buscar subsídios teóricos para aprimorar o cuidado ao portador de DP.

\section{Práticas da equipe de enfermagem no cuidado à criança com Doença de Pompe}

A equipe de enfermagem, em suas falas, se mostrou comprometida, envolvida afetivamente, com emoção, carinho, amor e orgulho por ter a oportunidade de cuidar de uma criança com DP. As profissionais enfatizaram experiências que superam procedimentos técnicos, na busca de fornecer um cuidado integral qualificado e seguro, para proporcionar vivências mais próximas de um lar para a criança e familiares.

[...] a gente tem que cuidar pra lateralizar, os bracinhos tem que cuidar, pra não deixar dobrado, as perninhas tem os travesseiros que coloca em baixo! E até as meias tem que cuidar pra não deixar dobrado! Até oxímetro, o fio, tem todo um cuidado. (P5)

[...] ela tem um cuidado integral que a meu ver é maravilhoso, nós temos um técnico em enfermagem que fica só com ela. (P10)

[...] exige muitos cuidados! Todos os movimentos dela retrocederam. Eu cuidei dela desde que ela veio pra cá, bebê. Ela se movimentava, as mãozinhas, as perninhas, ela dava tchauzinho, até saía umas palavrinhas, com o tempo isso foi retrocedendo. A gente criou um vínculo, ela é como se fosse da família, ela é moradora, né! Ela enxerga e já fica faceirinha, interage com o olhar. (P2) 
Sabe-se que a enfermagem é a ciência e a arte que assiste o ser humano em suas necessidades humanas básicas, com vistas a torná-lo independente por meio da educação para recuperar, manter e promover sua saúde ${ }^{21}$. Os cuidados da enfermagem com o paciente com DP devem atender a todas as suas necessidades, como ressaltado nas falas que seguem.

[...] aspiração e os cuidados de higiene, escovação dentária, banho no leito, fralda, mudança de decúbito a cada duas horas ou até menos! Ela não movimenta, então, do jeito que tu deixar, ela fica, tem que ter esse cuidado! A dieta também: lavar a sonda de jejunostomia, medicações via sonda, hidratação, aspiração, não sei se falei da traqueo? As vias aéreas! (P3)

[...] frequência respiratória dela, ela usa respirador! Ela usa o respirador portátil para passear aqui no hospital, na cadeirinha de rodas, toda arrumadinha. Isso ajuda ela! (P5)

A ventilação mecânica está vinculada a elevadas taxas de pneumonia, por isso foram desenvolvidas medidas para a prevenção de Pneumonia Associada à Ventilação Mecânica como medidas que contemplam tal demanda. Integram esse conjunto medidas como: manter cabeceira elevada de 30 a 45 graus; aspirar a secreção subglótica rotineiramente; e realizar higiene oral com antissépticos ${ }^{22}$.

Outro fator importante com relação aos cuidados de enfermagem é a forma como a comunicação é realizada entre a criança e equipe de enfermagem. Foram criadas estratégias para possibilitar uma comunicação com a paciente em processo progressivo da patologia, visto que com a comunicação verbal não é possível, assim como também a não verbal é comprometida pela imobilidade e atrofia muscular generalizada.

[...] ela com a face consegue expressar o que precisa, e a gente como está há muito tempo com ela, conseguimos entender o que ela quer! (P10)

[...] ela interage, ela responde ao estímulo, tu conversa com ela. Tu diz: tu quer ficar lá? Quer ficar viradinha para esse lado? A gente pergunta se quer o batonzinho, se sim faz o sinalzinho. Ela tem um sinalzinho que é assim, mexer a boca uma vez significa sim, mexer pra trás é não. Assim, ela consegue interagir da maneira dela, bem restrito mas a gente consegue ter uma comunicação. Daí a professora dela vem e conversa, sobre algumas coisas e pergunta: você tá entendendo? Ela faz com a boquinha, se sim ou se não. A gente consegue entender ela. (P3)

A atenção ao sujeito de forma holística, que o contemple em sua constituição biopsicossocial, precisa assegurar uma comunicação efetiva. Pesquisa desenvolvida com o objetivo de analisar o conceito de conforto em UTI pediátrica, na perspectiva dos profissionais de enfermagem, conduziu a reflexão quanto aos cuidados de enfermagem que são prestados à criança hospitalizada. Abordar o conforto diante de toda a tecnologia e comunicar-se com a criança traz benefícios para todos os envolvidos nesse cenário ${ }^{23}$. Essa afirmativa reforça o comprometimento da enfermagem com as necessidades do ser humano com a qualidade de vida.

Na perspectiva de uma atenção integral, o processo de enfermagem norteia e qualifica o cuidado, permitindo à equipe de enfermagem a avaliação constante do quadro de saúde do paciente, a identificação de problemas, o planejamento de intervenções e a avaliação das condutas realizadas, além de garantir o registro do cuidado desenvolvido, como é perceptível nas falas.

[...] dos diagnósticos de enfermagem ela tem: risco de integridade da pele; risco de infecção urinária; risco de sangramento em função da aspiração da traqueostomia; risco de infecção; risco de nutrição insuficiente. (P5)

[...] no sistema tem uma lista que a gente criou, ali tem os riscos e diagnósticos com intervenções pertinentes à paciente. (P9)

A Sistematização da Assistência de Enfermagem (SAE), no cuidado à criança, proporciona acolhimento efetivo da criança e familiares na internação hospitalar, pela compreensão que o enfermeiro possui na sua práxis e conhecimento científico $^{24}$. Já foi comprovado que a SAE promove melhorias permanentes e contínuas nas instituições, inclusive quando relacionado à gestão institucional, além de qualificar a assistência e gestão de processos de trabalho ${ }^{24}$. 0 cuidado relatado pela equipe de enfermagem é focado em promover uma assistência humanizada, considerando os aspectos biopsicossociais, com atuação da equipe multiprofissional em conjunto com familiares, para promover qualidade de vida à criança com DP.

\section{Limitações do estudo}

O estudo apresentou algumas limitações, como ter sido desenvolvida em uma única instituição privada, com uma equipe de enfermagem, porém esta equipe presta assistência a um portador de DP há aproximadamente oito anos, o que possibilitou desenvolver estratégias para qualificar a assistência, além de acompanhar a progressão da patologia. Essa limitação ocorreu pela raridade da patologia e pela oportunidade de intervenção com tratamento. São necessários estudos contínuos e aprofundados pela complexidade do tema e impacto na sociedade, com ênfase nos pacientes, familiares e profissionais envolvidos no processo de progressão da DP. 


\section{CONSIDERAÇÕES FINAIS}

O estudo demonstrou que a equipe de enfermagem apresenta os conhecimentos sobre a patologia necessários, integrando-se com as demais profissões para prestar um cuidado integral à criança com DP. Os cuidados desempenhados pela equipe vão além de práticas assistenciais de enfermagem, extrapolam os cuidados básicos desenvolvidos cotidianamente em uma UTI neonatal, não por considerar apenas a sua patologia, mas as necessidades humanas básicas. De tal forma, a equipe demonstrou, por meio das falas, mais do que técnicas e rotinas, vistas como a base da enfermagem, foram falas carregadas de empatia e, sobretudo, de equidade, adequadas para a fase de desenvolvimento do ser cuidado.

Publicações sobre a DP para a área da enfermagem ainda são escassas. Sugerem-se pesquisas sobre o tema, que possam auxiliar tanto a atuação técnica quanto a gestão dos cuidados de enfermagem. A publicação de estudos sobre cuidados de enfermagem a pacientes com doenças raras tem potencial para promover a saúde do paciente portador e favorecer a excelência do cuidado.

\section{REFERÊNCIAS}

1. van Gijn J. Pompe en zijn ziekte. Ned. tijdschr. geneeskd. [internet]. 2011 [cited 2020 Sep 12]; 155:A2878. Available from: https://www.ntvg.nl/system/files/publications/a2878.pdf.

2. Schoser B, Bilder DA, Dimmock D, Gupta D, James ES, Prasad S. The humanistic burden of Pompe disease: are there still unmet needs? A systematic review. BMC neurol. (Online). [internet]. 2017 [cited 2020 Set 12]; 17(1):202-19. DOI: https://doi.org/10.1186/s12883-017-0983-2.

3. Department of Health \& Human Services. Genetics Home Reference. Your guide to understanding genetic conditions [internet] Pompe disease. 2019. [cited 2020 Sep 12]. Available from: https://ghr.nlm.nih.gov/condition/pompe-disease.

4. Schoser B, Laforêt P, Kruijshaar ME, Toscano A, van Doorn PA, van der Ploeg A. Minutes of the European POmpe Consortium (EPOC) Meeting. Acta myologica [internet]. 2015 [cited 2020 Sep 12]; 34(2-3):141-3. Available from:

https://www.researchgate.net/publication/307989531_Minutes_of_the_European_POmpe_Consortium_EPOC_Meeting_Marc h_27_to_28_2015_Munich_Germany.

5. Pereira SJ, Berditchevisky CR., Marie SKN. Report of the first Brazilian infantile Pompe disease patient to be treated with recombinant human acid alpha-glucosidase. J. pediatr. (Rio J.) [internet]. 2008 [cited 2020 Sep 12]; 84(3): 272-5. DOI: https://doi.org/10.2223/JPED.1793.

6. Atherton AM, Day-Salvatore D. The Role of Genetic Counseling in Pompe Disease After Patients Are Identified Through Newborn Screening. Pediatrics. [internet]. 2017 [cited 2020 Sep 12]; 140(Suppl 1):46-50. DOI: https://doi.org/10.1542/peds.2016-0280F.

7. Parini R, De Lorenzo P, Dardis A, Burlina A, Cassio A, Cavarzere P, et al. Long term clinical history of an Italian cohort of infantile onset Pompe disease treated with enzyme replacement therapy. Orphanet j. rare dis. [internet]. 2018 [cited 2020 Sep 12]; 13(1):01-12. Available from: https://doi.org/10.1186/s13023-018-0771-0.

8. Hahn A, Praetorius S, Karabul N, Dießel J, Schmidt D, Motz R et al. Outcome of patients with classical infantile pompe disease receiving enzyme replacement therapy in Germany. JIMD rep [internet]. 2015 [cited 2020 Sep 12]; 20:65-75. Available from: https://doi.org/10.1007/8904_2014_392.

9. Broomfield A, Fletcher J, Davison J, Finnegan N, Fenton M, Chikermane A et al. Response of 33 UK patients with infantile-onset Pompe disease to enzyme replacement therapy. J. inherit. metab. dis. [internet]. 2016 [cited 2020 Sep 12]; 39: 261-71. Available from: https://doi.org/10.1007/s10545-015-9898-5.

10. Chen M, Zhang L, Quan S. Enzyme replacement therapies for infantile-onset Pompe disease. Cochrane database syst. rev. [internet]. 2017 [cited 2020 Sep 12]; 11(11):01-28. Available from: https://www.cochrane.org/CD011539/CF_enzymereplacement-therapies-infantile-onset-pompe-disease.

11. Nonose ERS, Matos APK, Silva RMM, Toninato APC, Zilly A, Lima RAG. Nursing care for children with Pompe disease: a case study. Online braz j. nurs. [internet]. 2018 [cited 2020 Sep 12]; 17(01): 140-50. Available from: https://doi.org/10.9789/21755361.2019.v11i5.1286-1292.

12. Lima RM, Gomes FMA, Aguiar FAR, Santos Júnior EB, Dourado JVL, Ferreira Junior AR. Experiences of Mothers During The Hospitalizatrion of Their Children. Rev. Pesqui. (Univ. Fed. Estado Rio J., Online). [internet]. 2019 [cited 2020 Sep 12]; 11(05):1286-92. Available from: https://doi.org/10.9789/2175-5361.2019.v11i5.1286-1292.

13. Dantas MAS, Nóbrega VM, Fechine CPNS; Torquato IMB; Assis WD, Collet N. Professional care for children with cerebral palsy and their families. Rev. enferm. UERJ. [internet]. 2017 [cited 2020 Sep 12]; 25:e18331. DOI: http://dx.doi.org/10.12957/reuerj.2017.18331.

14. Minayo MCS. Sampling and saturation in qualitative research: consensuses and controversies. Rev. Pesquisa Qualitativa. [internet]. 2017 [cited 2020 Sep 12]; 5(7):01-12. Available from: https://editora.sepq.org.br/index.php/rpq/article/view/82

15. Bardin L. Análise de conteúdo. São Paulo: Edições 70; 2011.

16. Semplicini C, Letard P, Antonio MD, Taouagh N, Perniconi B, Bouhour F, et al. Late-onset Pompe disease in France: molecular features and epidemiology from a nationwide study. J. inherit. metab. dis. [internet] 2018 [cited 2020 Sep 12]; 41(6):937-46. DOI: https://doi.org/10.1007/s10545-018-0243-7.

17. Buck ECS, Oliveira ELN, Dias TCC, Silva MFOC, França JRFS. Chronic disease and pediatric palliative care: nurses' knowledge and practice in light of human care. Rev. Pesqui. (Univ. Fed. Estado Rio J., Online) [internet]. 2020 [cited 2020 Set 12]; 12:682-8. 
Available from: http://seer.unirio.br/index.php/cuidadofundamental/article/view/9489.

18. Ministério da Saúde (Br). Secretaria de Ciência, Tecnologia e Insumos Estratégicos. Departamento de Gestão e Incorporação de Tecnologias em Saúde Coordenação de Avaliação e Monitoramento de Tecnologias. Alfa-alglicosidase como terapia de reposição enzimática na doença de Pompe [internet]. Brasília; 2019. [cited 2020 Set 12] Available from: http://conitec.gov.br/images/Consultas/Relatorios/2019/Relatorio_alfa-alglicosidase_Pompe_CP_33_2019.pdf.

19. Kishnani PS, Corzo D, Leslie ND, Gruskin D, Van der Ploeg A, Clancy JP et al. Early treatment with alglucosidase alpha prolongs long-term survival of infants with Pompe disease. Pediatr. res. [internet]. 2009 [cited 2020 Set 12]; 66(3):329-35. DOI: https://dx.doi.org/10.1203\%2FPDR.0b013e3181b24e94.

20. León-Ojeda NE, Seiglie-Díaz F, García-García A, Tápanes-Daumy H, Cañizares CV, Sánchez TA et al. Diagnosis and treatment of Pompe disease. Rev. cuba. pediatr. [internet]. 2016 [cited 2020 Set 12]; 88(03):375-87. Available from: http://scielo.sld.cu/scielo.php?script=sci_arttext\&pid=S0034-75312016000300011.

21. Ferreira JHP, Amaral JJF, Lopes MMCO. Nursing team and promotion of humanized care in a neonatal unit. Rev. RENE [internet]. 2016 [cited 2020 Set 12]; 17(6): 741-749. DOI: https://doi.org/10.15253/2175-6783.2016000600003.

22. Alecrim RX, Taminato M, Belasco A, Longo MCB, Kusahara DM, Fram D. Strategies for preventing ventilator-associated pneumonia: an integrative review. Rev. bras. enferm. [internet]. 2019 [cited 2020 Sep 12]; 72(2): 521-530. DOI: https://doi.org/10.1590/0034-7167-2018-0473.

23. Soares PR, Silva CRL, Louro TQ. Comfort of the child in intensive pediatric therapy: perception of nursing professionals. Rev. bras. enferm. [internet]. 2020 [cited 2020 Sep 12]; 73(4): e20180922. Available from: https://doi.org/10.1590/0034-7167-2018-0922.

24. Pissaia LF, Costa AEK, Moreschi C, Rempel C, Carreno I, Granada D. The impact of technologies in the implementation of hospital nursing assistance systematization: an integrative reviews. Rev. epidemiol. control. infec. [internet]. 2018 [cited 2020 Sep 12]; 08(01):92-100. DOI: http://dx.doi.org/10.17058/reci.v1i1.8953. 